\title{
Compound-component differentiation as a function of CS-US interval and CS duration in the rabbit's conditioned nictitating membrane response
}

\author{
E. JAMES KEHOE and BERNARD G. SCHREURS \\ University of New South Wales, Kensington, N.S.W., Australia
}

\begin{abstract}
The acquisition of the rabbit's nictitating membrane response to a tone + light compound and its components was examined as a function of the CS-US interval (Experiment 1) and CS duration (Experiment 2). In Experiment 1, responding to the compound attained high levels in all groups, but responding on component test trials declined to low levels as the CS-US interval increased across values of 300,800 , and $1,300 \mathrm{msec}$. Further disparities between the compound and components appeared when the animals were shifted to a positive patterning schedule. In Experiment 2, disparities between the compound and components increased as the duration of the CS was increased across values of 50,200 , and $800 \mathrm{msec}$ within a fixed CS-US interval of 800 msec. The results are discussed with respect to distributive processes, configuration, and speedaccuracy tradeoffs.
\end{abstract}

The present experiments were aimed at delineating the temporal dynamics of compound stimulus processing over the duration of a tone + light compound stimulus and its conditioned stimulus (CS)-unconditioned stimulus (US) interval. In Experiment 1, the level of responding to a compound and its components was examined as a function of the CS-US interval during reinforced compound training (Stage 1) and during a positive patterning schedule (Stage 2). In Experiment 2, the CS-US interval was fixed and CS duration was manipulated during reinforced compound stimulus training.

The present experiments stem from findings that disparities among the levels of responding to a compound and its components emerge as a direct function of the CS-US interval. In experiments using the cat paw flexion response (Wickens, Nield, Tuber, \& Wickens, 1970) and the rabbit nictitating membrane response (NMR) (Kehoe, 1982, 1986), animals were given reinforced presentations of a compound interspersed with tests of the separate components. Across groups, the CS-US interval was increased from values optimal for CR acquisition $(300-500 \mathrm{msec})$ to less optimal values $(1,300-2,000 \mathrm{msec})$. At the shorter CS-US intervals, the level of responding to the compound and the components reached high levels. At the longer CS-US intervals, responding to the compound continued to reach high levels, but responding to both components was negligible.

The positive effect of the CS-US interval on the disparity between compound and component response levels

This research was supported by Grant A28315236 from the Australian Research Grants Committee. The authors thank Maree Bell, John Hogan, and Patricia Spicer for their assistance in collecting the data. Correspondence should be sent to E. J. Kehoe, School of Psychology, University of New South Wales, Kensington, N.S.W., Australia 2033. may provide considerable insight into the temporal dynamics of stimulus processing in conditioning. In particular, the effects of the CS-US interval on compoundcomponent differentiation are relevant to the further development of real-time models of conditioning (e.g., Moore \& Stickney, 1980; Sutton \& Barto, 1981). In particular, these models have been aimed at detailing the precise effects of CS-US interval manipulations on CR acquisition. In addition, to account for phenomena involving compound stimulus processing, for example, overshadowing and blocking, the real-time models have incorporated one of the earlier distributive hypotheses, which did not address CS-US interval effects. Most notably, Moore and Stickney's (1980) model can be regarded as a real-time realization of the Mackintosh (1975) model, and Sutton and Barto's (1981) model can be regarded as a real-time realization of the Rescorla and Wagner (1972) model. Although there are substantial differences among the distributive hypotheses in either their original or real-time versions, they uniformly assume that the components of a compound remain functionally distinct but are processed in such a way that there is a tradeoff in the amount of associative strength gained by each of the contending stimuli (Mackintosh, 1975; Pearce \& Hall, 1980; Rescorla \& Wagner, 1972; Sutherland \& Mackintosh, 1971). Moreover, these distributive hypotheses assume that the level of responding to a compound reflects the net sum of the excitatory and inhibitory associative strengths of the components. Thus, the real-time models possess axioms for the effects of CS-US interval and axioms for the effects of compound stimuli. However, it is not clear whether this combination of axioms would predict a dramatic divergence between compound and component responding across CS-US intervals. A more appropriate 
selection of axioms might include an allowance for a configural process that yields a representation of the compound stimulus distinguishable from that of either component (e.g., Bellingham, Gillette-Bellingham, \& Kehoe, 1985; Kehoe, 1986; Kehoe \& Gormezano, 1980; Wickens et al., 1970). In order to provide an empirical basis for further identifying axioms describing the real-time character of compound stimulus processing, the present experiments were conducted to resolve (1) the practical limit of compound and component differentiation at each CS-US interval (Experiment 1), and (2) the effects of CS duration independent of CS-US interval (Experiment 2).

\section{EXPERIMENT 1}

The present experiment examined acquisition of the rabbit's NMR to a compound stimulus and its components as a function of the CS-US interval. The first stage of the experiment was designed to confirm earlier findings that the disparity between a compound and its components increased as the CS-US interval increased (Kehoe, 1982, 1986; Wickens et al., 1970). Since a compound conditioning procedure entails only an implicit discrimination between a compound and its components, the second stage of the present experiment examined the effects of the CS-US interval on an explicit compound-component differentiation procedure. Specifically, the animals were switched to a positive patterning schedule, in which reinforced compound presentations were intermixed with an equal number of unreinforced presentations of each component. Furthermore, the extension of training by itself could enhance the disparity between the compound and its components (e.g., Bellingham \& Gillette, 1981; Gray \& Lethbridge, 1976).

\section{Method}

\section{Subjects}

The subjects were 24 naive, female albino rabbits (Oryctolagus cuniculus). On arrival, each rabbit was 70-80 days old and weighed approximately $1.5 \mathrm{~kg}$. All rabbits had free access to food and water in their home cages.

\begin{abstract}
Apparatus
The apparatus and recording procedure for the nictitating membrane response were patterned after those of Gormezano (1966) and are detailed by Kehoe, Feyer, and Moses (1981). In brief, each subject was restrained in a Perspex box and trained in one of eight conditioning chambers. In each chamber, a speaker was mounted at a $45^{\circ}$ angle $8 \mathrm{~cm}$ anterior to and $16 \mathrm{~cm}$ above the subject's head. The speaker provided an auditory $\mathrm{CS}$, which was a 1000-Hz, 92 $\mathrm{dB}$ (SPL) tone superimposed on an ambient noise level of $81 \mathrm{~dB}$ provided by an exhaust fan. An $8-W$ frosted neon light tube was mounted $4 \mathrm{~cm}$ above the speaker. The light tube served as a houselight and was flashed at a rate of $20 \mathrm{~Hz}$ to provide a visual CS. The US was a 50-msec, 3-mA, 50-Hz ac shock delivered via stainless steel Autoclip wound clips positioned $10 \mathrm{~mm}$ apart and $15 \mathrm{~mm}$ posterior to the dorsal canthus of the right eye. The sequence and timing of stimulus events were controlled by an Apple II computer equipped with interfaces and software developed by Scandrett and Gormezano (1980).
\end{abstract}

The apparatus for transducing movements of the nictitating membrane differed in some respects from that described in previous reports. No straps were used to restrain the external eyelids. A chinrest (60 mm wide $\times 50 \mathrm{~mm}$ deep) was installed on the restrainer to ensure a uniform position of the head. The chinrest was mounted at a $30^{\circ}$ angle relative to horizontal. A muzzle-like headset, fitted about the snout of the rabbit, supported a transducer for monitoring movements of the nictitating membrane. A small tinned copper wire hook was attached to a silk loop sutured in the nictitating membrane of the rabbit's right eye. The other end of the wire hook contained a loop which fitted over another hook at the end of an L-shaped piano wire lever, which operated a photoelectric transducer (see Kehoe et al., 1981). The signal from the transducer was amplified and transmitted to an analog/digital converter installed in the computer.

\section{Procedure}

All rabbits received 1 day of preparation, 2 days of recovery, 1 day of adaptation, 8 days in Stage 1, and 8 days in Stage 2. On the preparation day, hair surrounding the rabbit's right eye was removed, a small loop of silk (000 Dynex) was sutured into the nictitating membrane, and the animals were returned to their home cages for 2 days of recovery. On the adaptation day, the animals were placed in the conditioning apparatus for $70 \mathrm{~min}$, but neither a CS nor a US was presented.

Following adaptation, the animals were assigned randomly to one of three groups $(n=8)$. The groups varied in terms of the length of the CS-US interval, and were designated C300, C800, and C1300, referring to $300-, 800$-, and 1300 -msec CS-US intervals (onset to onset), respectively. The duration of the CSs equaled the CS-US interval. In Stage 1, all groups were trained with a compound of light and tone. Each day of training contained 60 reinforced compound trials $(\mathrm{C}+)$, which were interspersed with 3 unreinforced test trials each of the compound $(C)$, tone (T), light (L), and background ( - ). This small number of test trials has been found to be insufficient for rabbits to acquire an explicit discrimination between a reinforced compound and unreinforced components (Kehoe \& Schreurs, 1986; Saavedra, 1975). A test trial was presented every sixth trial. The sequence of test trials was CTL-LCT-TLCon odd days and TLC-LCT-CTL - on even days. In Stage 2, all three groups were shifted to a positive patterning schedule. Each day, there were 23 reinforced compound trials $(\mathbf{C}+)$ interspersed with 23 unreinforced tone $\left(\mathrm{T}-\right.$ ) trials and 23 unreinforced light ( $\mathrm{L}_{-}$) trials. No more than three trials of one type occurred consecutively. In both stages, the mean intertrial interval (ITI) was $60 \mathrm{sec}$ (range $40-80 \mathrm{sec}$ ).

A conditioned response (CR) was defined as any extension of the nictitating membrane that exceeded $.5 \mathrm{~mm}$ and occurred following the onset of the CS but prior to its termination. Unless otherwise noted, planned contrasts were used to analyze the data, and the rejection level was set according to a Type I error rate of .05 .

\section{Percent CR}

\section{Results}

Stage 1. Panels a, b, and c of Figure 1 show the mean percentage of CRs as a function of days for Groups $\mathrm{C} 300$, $\mathrm{C} 800$, and $\mathrm{C} 1300$, respectively. The left half of each panel depicts $C R$ acquisition to the compound, the tone, and the light during compound conditioning (Stage 1); the right half shows responding during the positive patterning schedule (Stage 2).

As illustrated in the left half of each panel, CR acquisition to the compound $(\mathrm{C}+)$ varied as a function of the CS-US interval. Group C300's performance exceeded 90\% CRs by Day 2 of training; Groups C800 and C1300 reached that level by Day 4 . The overall levels of responding to the compound for Groups C300, C800, and C1300 were $92 \%, 72 \%$, and $78 \%$ CRs, respectively. Statistical 


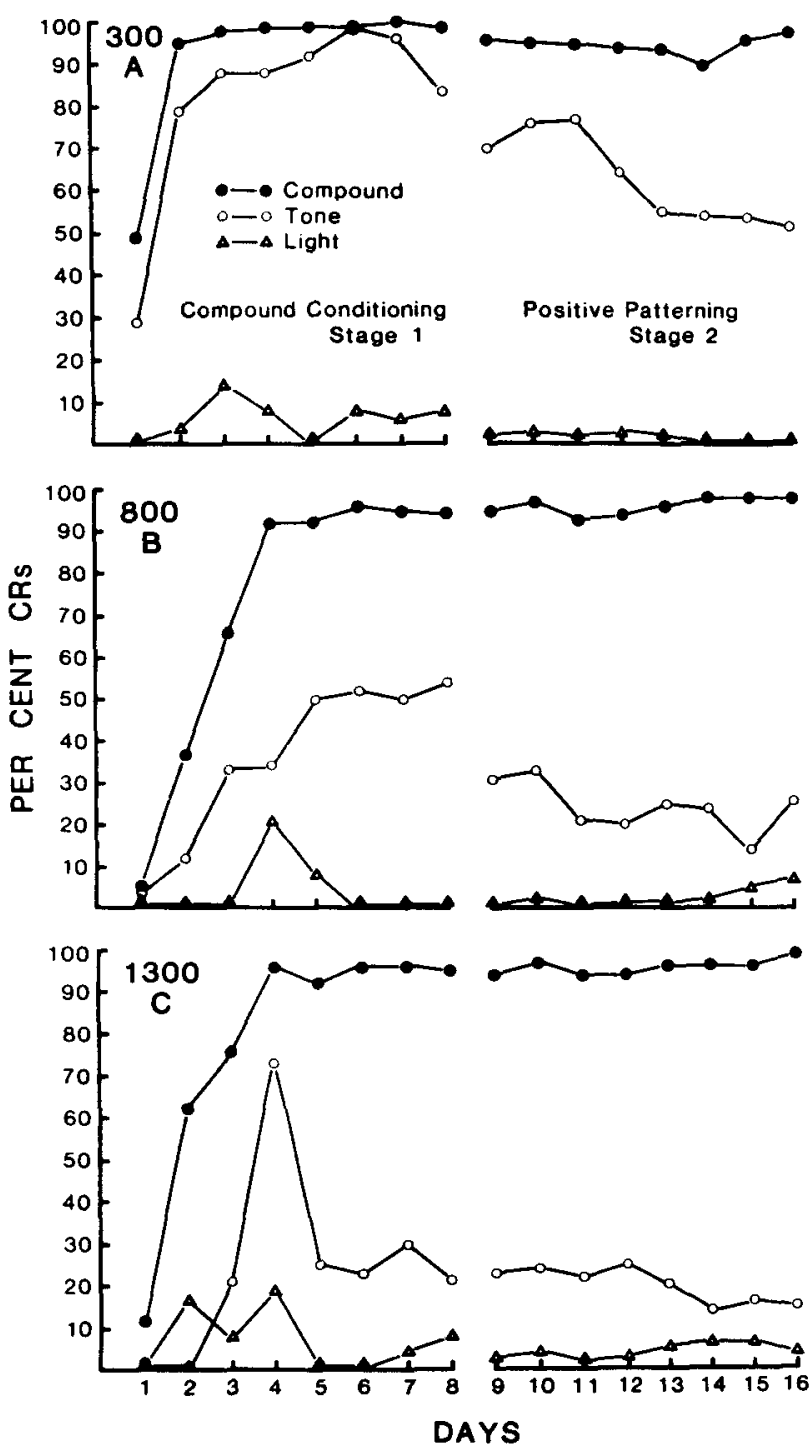

Figure 1. Mean percentage CRs to the compound, tone, and light as a function of days in Experiment 1. The left-hand column of panels shows the acquisition curves during reinforced compound training (Stage 1) across CS-US intervals of 300,800 , and 1,300 msec. The right-hand column of panels shows the levels of responding during a subsequent positive patterning schedule (Stage 2).

analysis revealed that there were significant linear and quadratic trends in the overall compound response levels across the CS-US intervals $\left[F_{\mathrm{S}}(1,21)=38.50\right.$ and 11.07 , respectively]. The level of responding to the tone varied even more dramatically as a function of CS-US interval. The overall mean percentage CRs on tone test trials for Groups $\mathrm{C} 300$, C800, and $\mathrm{C} 1300$ were $82 \%, 36 \%$, and $24 \%$ CRs, respectively (linear trend) $[F(1,21)=50.58]$. Responding on light test trials was uniformly low in all groups, never exceeding 20\% CRs throughout training. The overall mean percentage CRs on light test trials for Groups $\mathrm{C} 300, \mathrm{C} 800$, and $\mathrm{C} 1300$ were $6 \%, 4 \%$, and $7 \%$ CRs, which failed to differ significantly.
In general, the level of responding to the compound was higher than responding to either tone or light. The difference between the levels of responding to the compound and the tone increased as a direct function of the CS-US interval (linear trend) $[F(1,21)=36.07]$. In Group C300, the difference was small and failed to reach statistical significance $[F(1,21)=3.31, p<.10]$. At the end of Stage 1, only two subjects in Group C300 showed a higher level of responding to the compound than to the tone. However, in Groups C800 and C1300, the compound versus tone comparisons were significant $[F \mathrm{~s}(1,21)=$ 45.98 and 106.37]. At the end of Stage 1, Group C800 contained six animals which showed greater responding to the compound than to the tone and Group C1300 contained seven such animals. The difference between compound and light response levels was large in all subjects in all three groups [smallest $F(1,21)=303.05$ ].

Stage 2. Examination of the right-hand panels in Figure 1 reveals that all groups in Stage 2 continued to show high levels of responding to the compound and nearzero levels of responding to the light during the positive patterning schedule. However, responding to the tone generally showed appreciable declines following the shift to a positive patterning schedule. In Group $\mathrm{C} 300$, responding to the tone declined from $83 \%$ CRs at the end of Stage 1 to $70 \%$ CRs on the first day of Stage 2, which was followed by a further decline to $52 \% \mathrm{CRs}$ at the end of Stage 2. Likewise, in Group C800, the level of responding to the tone declined from $54 \%$ CRs to $31 \%$ CRs on the first day of Stage 2 and to $21 \%$ CRs on the last day of Stage 2. Finally, Group C1300 actually showed a small rise in responding to the tone from $21 \%$ CRs to $23 \%$ CRs, but that was followed by a decline to $15 \%$ CRs. Statistical analysis confirmed that across all three groups there was a significant drop in responding to the tone from Day 8 (Stage 1$)$ to Day 9 (Stage 2$)[F(1,21)=4.27]$. In addition, there was a significant downward linear trend in responding to tone over the course of Stage $2[F(1,21)$ $=6.85]$. A detailed examination of the data revealed that every subject showed a higher level of responding to the compound than to the components during Stage 2 training. The statistical analysis revealed that, as in Stage 1, the magnitude of differentiation between the compound and the tone increased as a function of CS-US interval (linear trend) $[F(1,21)=22.00]$. The large differences in responding to the compound versus the light apparent in Stage 1 continued through Stage 2 without regard to CS-US interval $[F(1,21)=6,791.63]$.

\section{CR Latency}

Figure 2 depicts the frequency distribution for CR latencies on reinforced compound trials for Days $2,4,6$, and 8 in Stage 1. In addition, distributions are shown for Days 12 and 16, which were in Stage 2. Each panel represents a different day and shows separate distributions for Groups $\mathrm{C} 300, \mathrm{C} 800$, and C1300. Each distribution is an aggregate of the CRs of all the animals in each group. The distributions for Days 12 and 16 are lower only because there 

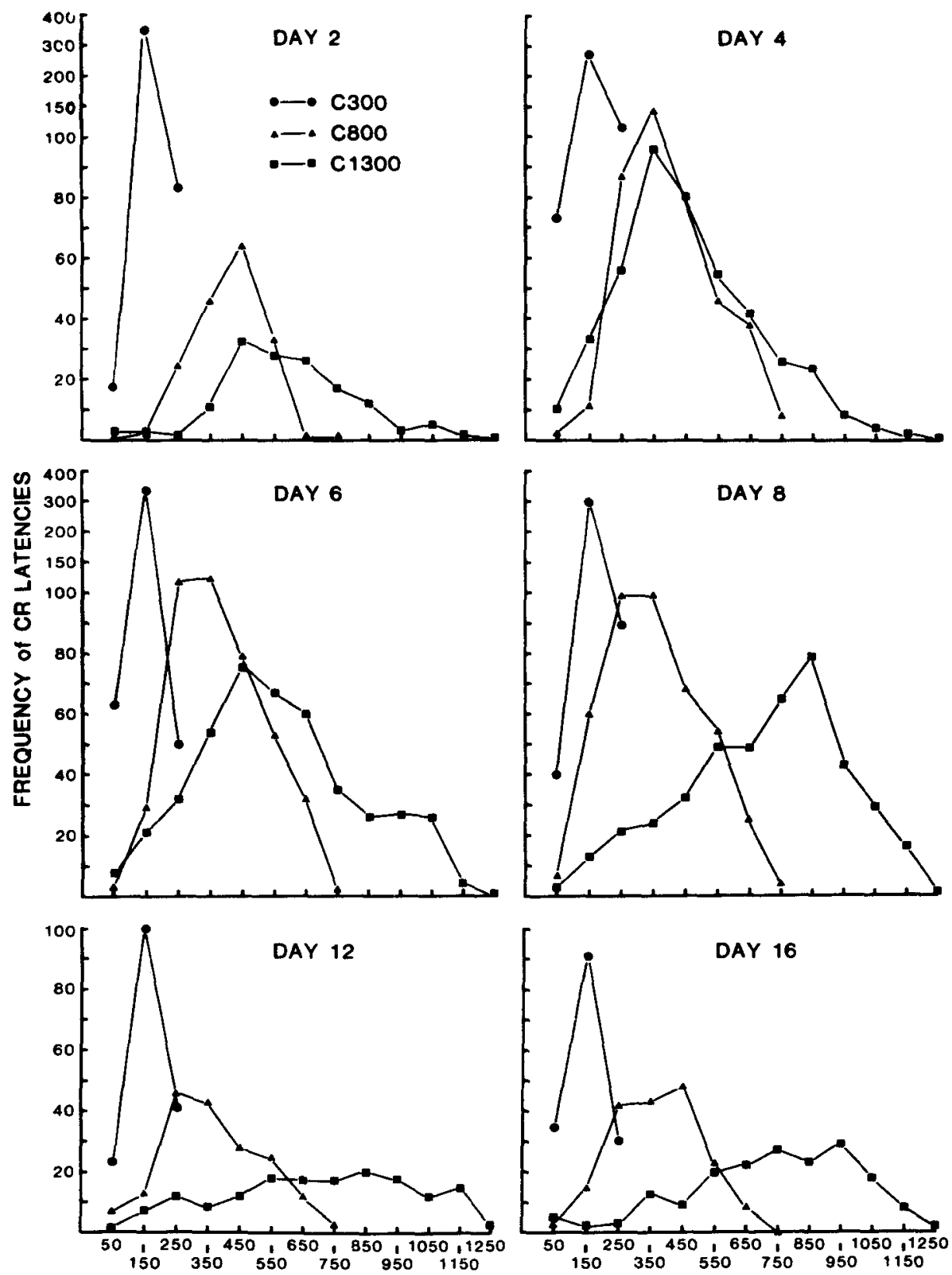

MIDPOINT of 100-ms BINS

Figure 2. Frequency polygons for CR latency obtained from reinforced compound trials in Groups $\mathrm{C300}, \mathrm{C800}$, and $\mathrm{C1300}$ of Experiment 1 . Note that the ordinate scale is progressively compressed above 100. The polygons for Days 2-8 are each based on 480 observations (60 reinforced trials $\times$ 8 subjects), and the polygons for Days 12 and 16 are based on 184 observations (23 reinforced trials $\times 8$ subjects).

were fewer reinforced compound trials during the positive patterning schedule in Stage 2 than during the compound conditioning schedule in Stage 1. The CR latencies are grouped in 100-msec bins, and, on the abscissa, each bin is designated by its midpoint. The reader should note that the frequency scale on the ordinate is progressively compressed above 100 .
The presentation of $C R$ latency distributions is restricted to compound trials, because it was very difficult to obtain a clear picture of the CR latency on tone and light test trials. In particular, there were relatively few CRs on those trials, and, even where CRs appeared on test trials, there were only three test trials of each per session. In what could be seen, the distributions of CR laten- 
cies on tone test trials in Groups $\mathrm{C} 300$ and C800 paralleled those obtained on compound trials. There were so few CRs on tone test trials in Group C1300 and on light test trials in all groups that their distributions were very low and apparently flat.

Inspection of Figure 2 reveals that the CR latency increased with the CS-US interval. Specifically, all subjects in Group C300 displayed a modal CR latency of $150 \mathrm{msec}$ throughout training. Group C800 showed a gradual decline in its modal latency from $450 \mathrm{msec}$ on Day 2 to approximately $300 \mathrm{msec}$ by Day 6 . Among individual subjects in Group C800 on Day 8, 5 subjects displayed modal latencies in the range of $200-400 \mathrm{msec}$. Group C1300's modal latency initially showed a decrease similar to that displayed by Group C800. However, from Day 6 onward, Group C1300 showed increases in the modal latency, which reached $850 \mathrm{msec}$ by Day 8 . The modal latencies of individual subjects in Group C1300 on Day 8 ranged from 450 to $950 \mathrm{msec}$. The group distributions on Day 8 were compared statistically in a pairwise fashion using the chi-square test for differences between two distributions in their relative (not absolute) frequencies across bins. To prevent the multiple comparisons from inflating the overall Type I error rate, the error rate for each test was set to .01. Because the groups differed in their CS-US intervals, comparisons could only be made for the initial bins. In general agreement with the observations concerning modal latency, it was confirmed that Group C300's distribution differed from the first three bins of Group C800's and Group C1300's distributions $\left[\chi^{2}(2, N=590)=83.39\right.$ and $\chi^{2}(2, N=461)=$ 24.82]. Furthermore, Group C800's distribution differed significantly from that of Group C1300 in its first eight bins $\left[\chi^{2}(7, N=675)=175.41\right]$. Following the end of Stage 1 on Day 8, the introduction of the positive patterning schedule in Stage 2 did not appear to alter the distribution of CR latencies in any of the three groups.

\section{Discussion}

The results of compound conditioning in Stage 1 confirm earlier findings that the disparity in the levels of responding to a compound and its components increased across CS-US intervals (Kehoe, 1982, 1986; Wickens et al., 1970). In the present case, the increasing disparity was confined to the compound and the tone, because the animals in all three groups showed minimal responding to the light. The results of Stage 2 indicated that explicit discrimination training and/or continued training could induce further disparities between the compound and tone, even at the shortest CS-US interval. At the end of Stage 2, the relative levels of responding to the compound and its components indicated that the process underlying compound-component differentiation was well engaged by the time $300 \mathrm{msec}$ had elapsed and was virtually complete by $800 \mathrm{msec}$.

The virtual absence of responding to the light in all three groups was almost certainly an instance of overshadowing. Although the present experiment did not include single stimulus control conditions, previous experiments have included groups that received reinforced training with either the light (Kehoe, 1982) or mixtures of light trials and tone trials (Kehoe, 1986). As required by the definition of overshadowing (Kamin, 1969), Kehoe (1982, 1986) demonstrated both (1) substantial CR acquisition to the light and tone in the single stimulus conditions and (2) reductions in CR acquisition to the light in the compound groups. Although the light in the present experiment evoked only minimal responding, the light nevertheless appeared to be a functional component of the compound in all groups. Had light played no part in responding to the compound, the levels of responding to the compound and the tone would have been identical at all CS-US intervals. Moreover, increases in the disparity between the compound and the tone during Stage 2 training would have been impossible.

In the present results, the increase in $C R$ latencies across CS-US intervals paralleled the increase in the disparity between the compound and tone response levels across CS-US intervals. As the simplest interpretation, the parallel between $C R$ latency and $C R$ percent measures could be construed as indicating that CR latency is simply another index of excitatory associative strength along with the percent CR measure. However, the use of CR latency as an index of excitatory associative strength is complicated by its sensitivity to time-related inhibitory processes as was seen in the increase in CR latency midway through Stage 1 training for Group C1300. Thus, in Group C1300, the speed of the CR was decreasing while the CR likelihood was still increasing.

The overall parallel between $C R$ latency and the compound-component disparity may also be described as a speed-accuracy tradeoff in that differentiation between a compound and its components depends on the time available for processing of the stimuli prior to response output (Frey, 1969; Hartman \& Grant, 1962). In differential conditioning between CSs varying along a simple physical dimension, differentiation increases as the CS-US interval on CS+ trials increases. For example, Vandercar and Schneiderman (1967) reported that tone frequency discrimination in the rabbit NMR preparation improved when the CS-US interval on CS+ trials was $750 \mathrm{msec}$ rather than $250 \mathrm{msec}$ (cf. Chisholm, Hupka, \& Moore, 1969; Frey, 1969; Hartman \& Grant, 1962). Presumably, training with the shorter CS-US interval biases the animal to make a rapid response with a resulting loss of accurate stimulus processing. Conversely, training with the longer CS-US interval permits a slower response, giving more time for accurate processing of CS+ and CS- (Hartman \& Grant, 1962). Application of the speed-accuracy hypothesis to compound stimulus processing would have to assume that a configural interaction between the concurrent CSs provides the foundation for distinguishing a compound from its components.

\section{EXPERIMENT 2}

Experiment 2 examined the effects of CS duration on the level of responding to a compound and its components. 
Like Experiment 1, previous studies of compound conditioning have routinely used a delay conditioning procedure in which the CS duration equaled the CS-US interval (Kehoe, 1982, 1986; Wickens et al., 1970). The present experiment was designed to disentangle those two variables. Specifically, the CS-US interval was fixed at $800 \mathrm{msec}$ and the CS duration was varied across values of 50, 200, and $800 \mathrm{msec}$. According to distributive theories, increases in CS duration should increase the opportunity to process either one or both CSs in a compound and thereby lead to an increase in responding to at least one of the CSs (see Lamb \& Riley, 1981). From the viewpoint of configural hypotheses, it would seem likely that short CS durations would provide insufficient time for the configural interaction between representations of the individual components. Thus, configural hypotheses predict the disparity between the compound and component response levels to be small at the shorter CS durations and to increase at the longer CS durations. Finally, a simple version of a speed-accuracy hypothesis would predict a constant disparity between the compound and component response levels across CS durations, because the constant CS-US interval would equate the objective time demands on response generation across groups.

\section{Method}

Subjects

The subjects were 24 naive, female albino rabbits, $70-80$ days old and weighing approximately $1.5 \mathrm{~kg}$ on arrival.

\begin{abstract}
Apparatus and Procedure
Unless otherwise noted, the apparatus and procedure were identical to those used in Experiment 1. All rabbits received 1 day of preparation, 2 days of recovery, 1 day of adaptation, and 10 days of training. On each day of training, all groups received 60 reinforced presentations of the tone + light compound interspersed with 3 unreinforced test trials each of the compound, tone, light, and background. The animals were assigned randomly to one of three groups $(n=8)$. The groups varied in CS duration, which was 50 , 200 , or $800 \mathrm{msec}$. Accordingly, the groups were designated D50, D200, and D800, respectively. Within each group, CS duration was constant across reinforced and test trials. The CS-US interval was $800 \mathrm{msec}$ in all three groups.

A conditioned response (CR) was defined as any extension of the nictitating membrane that exceeded $.5 \mathrm{~mm}$ and occurred within an 800 -msec interval after CS onset. Planned contrasts were used to analyze the data, and the rejection level was set according to a Type 1 error rate of .05 .
\end{abstract}

\section{Results}

Figure 3 shows the mean percentage of CRs for all three groups. Each panel depicts CR acquisition to the compound, tone, and light stimuli across the days of training. Inspection of Figure 3 reveals that the rate of $C R$ acquisition to the compound $(\mathrm{C}+)$ was a positive function of the CS duration. Group D50 reached a mean level of only $50 \%$ CRs at the termination of training, whereas Groups D200 and D800 reached that level by Days 5 and 3 , respectively. The positive relation between CS duration and the rate of $\mathrm{CR}$ acquisition to the compound parallels the previous results of comparisons between trace conditioning, in which the CS duration is shorter than the
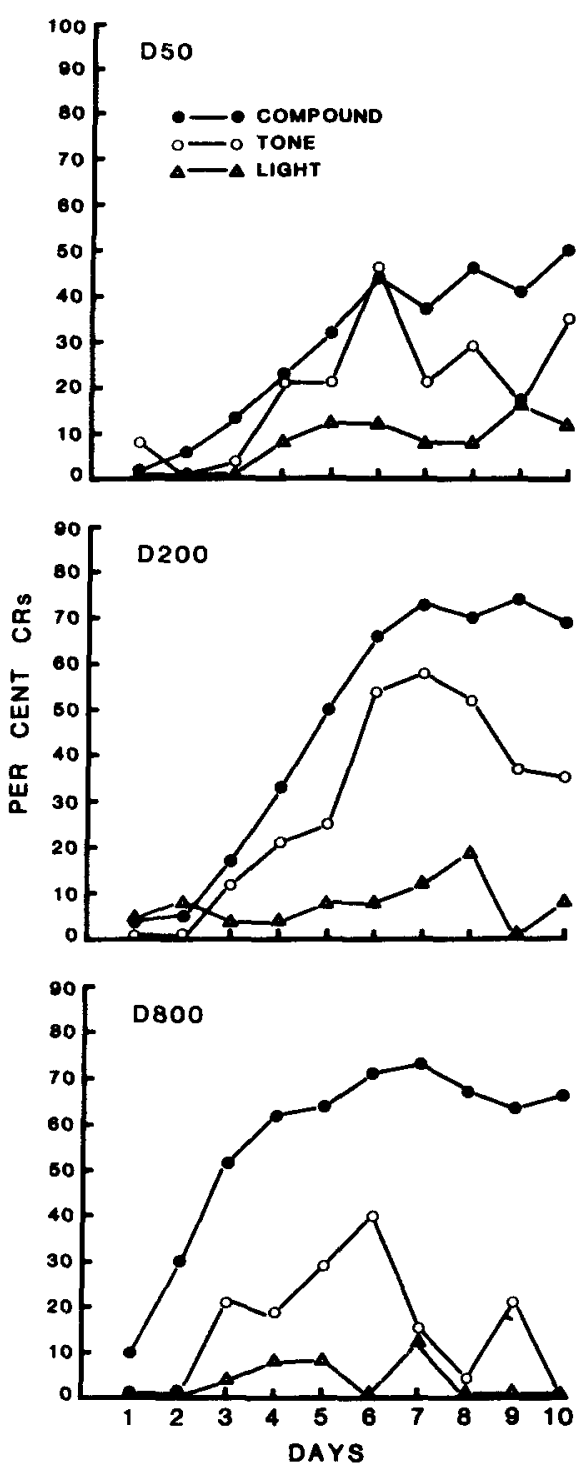

Figure 3. Mean percentage CRs to the compound, tone, and light as a function of days across CS durations of 50,200 , and $800 \mathrm{msec}$ in Experiment 2.

CS-US interval, and delay conditioning, in which the CS duration at least equals the CS-US interval (Schneiderman, 1966). The level of responding on tone test trials in all groups rose through the first half of training and then declined during the latter half of training. The level of responding on tone test trials was generally higher in Group D200 than in Groups D50 and D800. In all three groups, the level of responding to the light was negligible.

Figure 4's left-hand panel shows the mean levels of responding to the compound, tone, and light over all 10 days of training as a function of CS duration. As can be seen, the overall level of responding to the compound rose as a positive function of the CS duration. In contrast, the level of responding to the tone appeared to follow a bitonic function with its maximum at the 200-msec CS duration. The levels of responding to the compound and the 
tone appeared to diverge as the CS duration increased. The level of responding to the light was generally low and distinct from the compound response level at all three CS durations. The statistical analysis confirmed that the level of responding to the compound was greater than the level of responding to the tone $[F(1,21)=67.16]$, but the size of the difference interacted with the CS duration (linear component) $[F(1,21)=21.95]$. Likewise, the compound versus light difference was significant $[F(1,21)=$ 76.91] and interacted with the CS duration (linear component) $[F(1,21)=8.70]$.

Figure 4's right-hand panel shows the mean "discrimination ratios" for (1) the disparity in compound and tone response levels and (2) the disparity in compound and light response levels on Day 10. The disparity in responding to the compound and each component was expressed as a discrimination ratio computed by dividing the percent CRs to the compound by the sum of the percent CRs to the compound and that component. These discrimination ratios were used to compare the compound versus component disparities while eliminating the main effect of CS duration on overall levels of responding. As can be seen in Figure 4, the discrimination ratios were positively related to CS duration (linear trend) $[F(1,20)=27.25]$. In addition, the discrimination between the compound and the light was greater than discrimination between the compound and the tone. However, this latter difference did not reach statistical significance $[F(1,20)=4.06$, $p<.10]$.

Figure 5 depicts the frequency distribution for $C R$ latencies on reinforced compound trials for Days $2,4,6,8$, and 10. Each panel represents a different day and shows the separate distributions of Groups D50, D200, and D800. Each distribution is an aggregate of the CRs of all the animals in each group. The CR latencies were grouped in 100-msec bins, and, on the abscissa, each bin is designated by its midpoint. As in Experiment 1, it was very difficult to obtain a clear picture of the CR latency on tone and light test trials, because there were only three trials

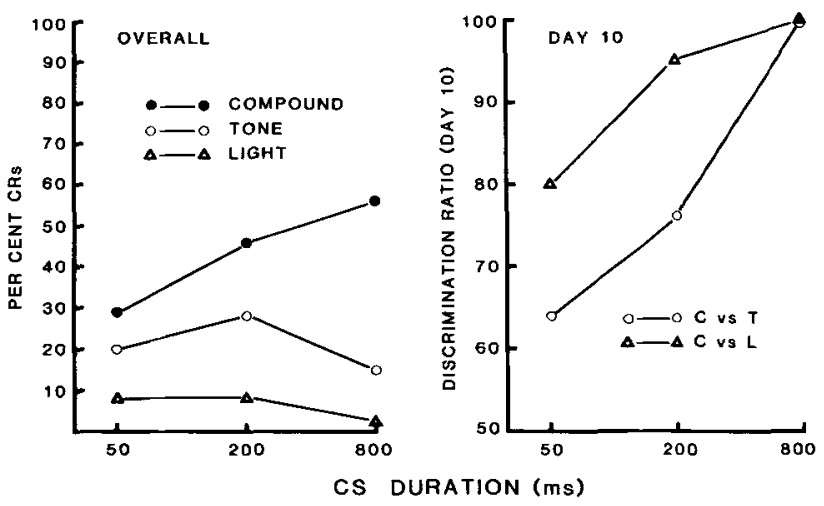

Figure 4. The left-hand panel shows the overall mean percentage CRs to the compound, tone, and light as a function of CS duration in Experiment 2. The right-hand panel shows the mean discrimination ratios for (a) the compound versus the tone and (b) the compound versus the light as a function of CS duration on Day 10 of Experiment 2. of each per session and there were relatively few CRs on those trials.

Inspection of Figure 5 reveals that CR latency appeared sensitive to CS duration. In groups D50 and D200, in which the CS occupied only the initial portion of the CS-US interval, bimodal latency distributions emerged as training progressed. This bimodality did not appear in the distributions of individual subjects, since their distributions were unimodal. Instead, the bimodality of the group distributions represented a divergence among the subjects' individual distributions. On Day 10, Group D50 contained 3 subjects that showed a modal latency less than $300 \mathrm{msec}$ and 3 subjects that showed a modal latency greater than $600 \mathrm{msec}$. The remaining 2 subjects in Group D50 showed such low levels of responding that they had essentially flat distributions. Similarly, Group D200 had 3 subjects showing a modal latency less than $300 \mathrm{msec}$, 4 subjects showing a modal latency greater than $600 \mathrm{msec}$, and one subject showing a low, flat distribution. In Group D800, in which the CS filled the entire CS-US interval, the distributions of CR latencies for the group and the individual subjects were unimodal. Although Group D800's distributions were unimodal throughout training, there appeared to be systematic shifts resembling those seen in Group C1300 of Experiment 1. In Group D800, the modal CR latency was located at the midpoint of the CS-US interval on Day 2. As training progressed, Group D800's modal CR latency gradually increased. By Day 10 , only 1 subject showed a modal latency less than $300 \mathrm{msec}$ and 5 subjects showed modal latencies greater than $500 \mathrm{msec}$. The other 2 subjects showed modes between 300 and $500 \mathrm{msec}$. Analysis of the group latency distributions on Day 10 was conducted with chi-square tests using a .01 level of significance. These tests confirmed that Group D200's apparently bimodal distribution differed significantly from Group D800's apparently unimodal distribution $\left[\chi^{2}(7, N=588)=51.88\right]$. However, Group D50's apparently bimodal distribution failed to differ significantly from either that of Group D200 $\left[\chi^{2}(7, N=542)=\right.$ $15.19]$ or that of Group D800 [ $\left.\chi^{2}(7, N=502)=15.19\right]$.

\section{Discussion}

The results of Experiment 2 reveal that variation in CS duration alone alters the disparity in responding to the compound versus the components. The increase in the compound-component disparity across CS durations challenges the distributive hypotheses, which would have predicted responding to at least one of the components to rise along with that of the compound. The present results also indicate that speed-accuracy tradeoffs may contribute relatively little to the compound-component disparity. Since the fixed 800 -msec CS-US interval imposed a uniform time requirement on the response-generation process, there should have been a constant difference between the compound and component response levels. However, the direct effect of CS duration on the disparity between compound and component response levels could be interpreted as reflecting an implicit time con- 

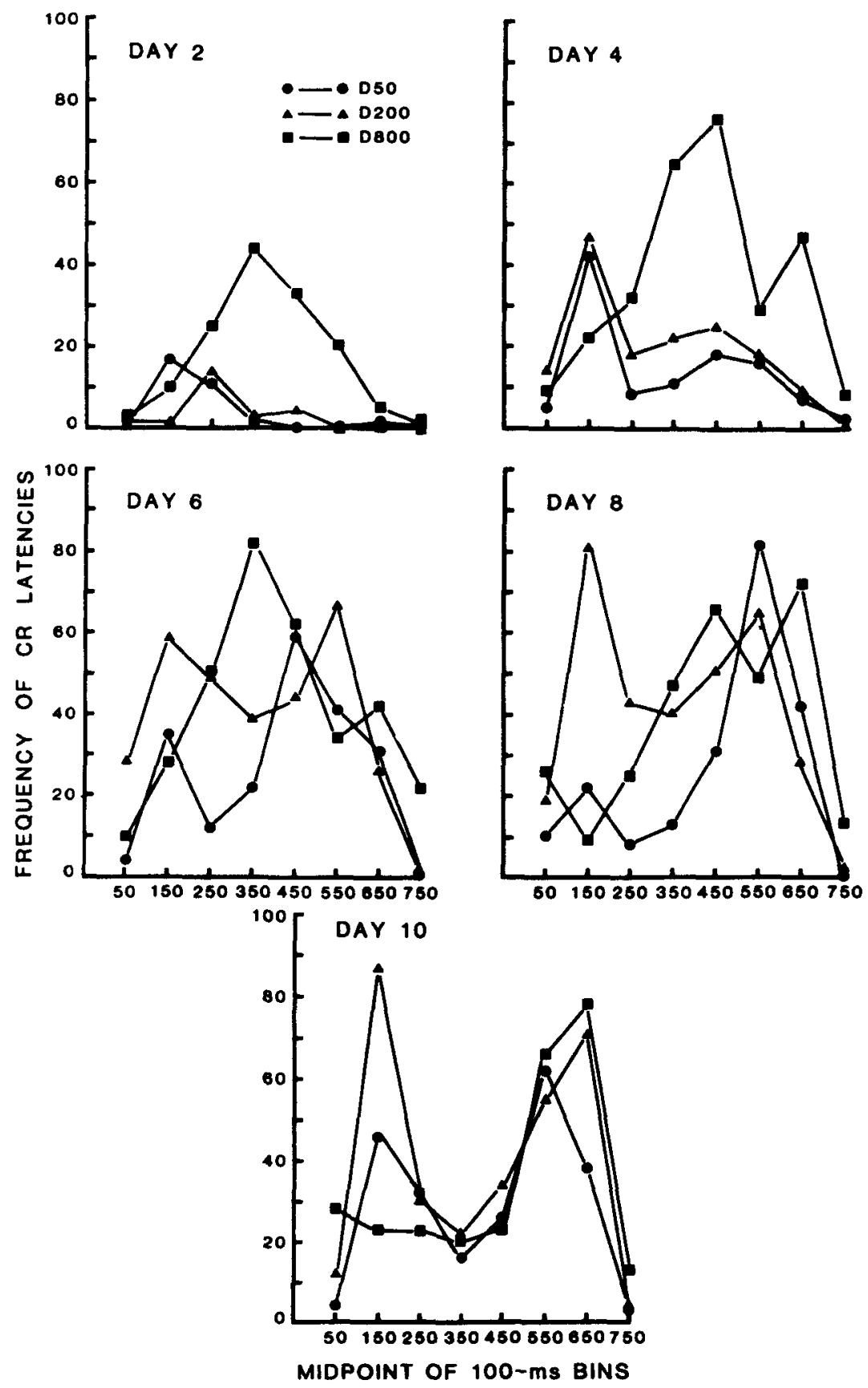

Figure 5. Frequency polygons for $\mathrm{CR}$ latency obtained from reinforced compound trials in Groups D50, D200, and D800 of Experiment 2. The polygons for each day are based on 480 observations ( 60 reinforced trials $\times 8$ subjects).

straint on the response output process. For example, it could be argued that, with the offset of a short-duration compound stimulus, its representation begins to decay and become increasingly indistinguishable from those of its components. However, such an interpretation shifts the theoretical focus away from direct time constraints on responding toward the temporal dynamics of stimulus processing. On the positive side, the increase in the compound-component disparity across CS duration dis- tinctly favors a configural hypothesis which contends that the perceptual interaction between the individual components requires a period of exposure to the stimuli ranging up to several hundred milliseconds.

\section{GENERAL DISCUSSION}

The major findings of the present experiments were as follows: (1) Joint increases in the CS-US interval and CS 
duration produced increases in the disparity between the levels of responding to a tone + light compound and its components under both reinforced compound training (Experiment 1, Stage 1) and subsequent positive patterning (Experiment 1, Stage 2); (2) increases in CS duration within a fixed CS-US interval produced increases in the disparity between the compound and component response levels under reinforced compound training (Experiment 2); (3) variations in the disparity between the compound and its components were largely confined to differences between the compound and tone response levels, because the light in all groups evoked minimal responding throughout training; (4) modal CR latency was a direct function of the CS-US interval in Experiment 1; and (5) modal CR latencies tended to diverge among subjects under the 50- and 200-msec CS durations in $\mathrm{Ex}$ periment 2 .

\section{Atomistic Summation}

In interpreting the present results, the need for parsimony requires that consideration be given to a simple summation principle. That is to say, the level of responding to the compound could represent a summation of the independent associative strengths of the tone and the light. In the case of the light, its associative strength would presumably have some subthreshold value. The mere fact that the level of responding to the compound was higher than that of the components is consistent with a summation principle. However, the summation principle encounters difficulty in the changing relationship between the compound and the components. Across CS-US intervals in Experiment 1, responding to the tone declined systematically, whereas responding to the compound uniformly reached asymptotic levels near $100 \%$ CRs. Across CS durations in Experiment 2, the level of responding to the tone remained relatively constant, whereas the level of responding to the compound reached progressively higher overall levels, asymptotically hovering around $75 \%$ CRs, well below the measurement ceiling. To explain the relationship between the compound, tone, and light for any single group, a defender of the summation principle could argue that there was a nonlinear mapping of associative strength onto responding. However, when the level of responding to the tone descends through virtually the entire response scale and responding to the compound remains largely unchanged, it is difficult to see how any single mapping function, linear or nonlinear, could reasonably account for the entire set of results.

\section{Distributive Theories}

Distributive theories would contend that the light's representation in the present experiment failed to capture either sufficient associative strength (e.g., Rescorla \& Wagner, 1972) or attentional capacity (e.g., Sutherland \& Mackintosh, 1971) to be able to command any responding. By the same token, distributive theories would predict that the tone's representation should have captured nearly all the available associative and/or attentional capacity, thus commanding substantial levels of responding. However, the virtual disappearance of responding to the tone as well as light across increases in the CS-US interval and CS duration runs counter to the expectations of distributive theories on two counts. First, the tone should have evoked some responding across all manipulations. Second, as the increases in CS-US interval and CS duration increased the time available for processing of the components, the level of responding to the tone and/or light should have increased rather than decreased. A staunch defender of distributive theories could attempt to deflect the absence of responding to either component by contending that the tone and light possess subthreshold associative strengths, which might be revealed by subsequent savings tests. Similarly, the increasing rather than decreasing compound-component disparity across CS-US interval and CS duration could reflect the conventional effects of these variables, both of which tend to diminish CR acquisition to single CSs (e.g., Schneiderman, 1966). However, appeals to such mitigating factors risk depriving distributive theories of their testability.

\section{Configural Hypotheses}

The configural hypotheses can generally account for the present pattern of results, particularly the failure of many animals to respond to either component while maintaining a high level of responding to the compound. However, this explanatory power is achieved at the cost of some indeterminancy. Although the configural hypotheses have all contended that the representations of the CSs interact to produce distinctive compound-related representations, these hypotheses have only vaguely specified the rules governing the synthesis of the compound-related representations and/or the perceptual distance between a compound and its components (Kehoe \& Gormezano, 1980). In brief, these rules have remained largely a matter of empirical inference. Among the configural hypotheses, many have assumed that the results of tests with components outside the context of the compound presumably reflect the degree of generalization (or lack thereof) from their representations inside the compound (Baker, 1972; Bellingham et al., 1985; Heinemann \& Chase, 1975; Hull, 1943, 1945; Kehoe \& Gormezano, 1980, pp. 370-373; Razran, 1965, 1971; Young \& Pearce, 1984). From the present results, it could be inferred that, over the first 200-300 msec of CS presentation, the interaction between the representations of the components produces a compound representation that differs markedly from the light but not from the tone. However, it would be a mistake to assume that after $200-300 \mathrm{msec}$, the nervous system has ceased processing the light. Instead, it appears that processing of both components continues such that, over longer intervals, the emerging compound representation differs markedly from both the tone and the light when presented in isolation. In Stage 2 of Experiment 1, the increase in differentiation between the compound and the tone during positive patterning poses little difficulty for configural hypotheses. Their advocates could argue that 
the unreinforced presentations of the components endowed their separate representations with an inhibitory potential that did not generalize strongly to the reinforced compound.

\section{The Unique Stimulus Hypothesis}

Although distributive and configural hypotheses would appear to be mutually exclusive, the unique stimulus hypothesis has been used to incorporate a configural process into the otherwise distributive Rescorla-Wagner (1972) model (Bellingham et al., 1985; Holland \& Block, 1983; Rescorla, 1972, 1973; Whitlow \& Wagner, 1972). The unique stimulus hypothesis assumes that the compound stimulus produces an extra stimulus which has the ability to acquire an associative strength independent of those acquired by the separate components. Thus, a twocomponent compound consists of the two separable elements and its unique stimulus, all of which would compete for associative strength on a reinforced compound presentation. If the unique stimulus has a high salience, then the separable elements would gain relatively little associative strength and, accordingly, evoke a relatively low level of responding on tests of the components. The present results suggest that the recruitment of the unique stimulus proceeds somewhat more slowly than the recruitment of the elements. On the basis of the present findings, it could be argued that the representation of a single CS reaches its maximal salience some time within the first 200-300 msec of presentation. However, since complete differentiation between the compound and components required a CS-US interval between 800 and $1,300 \mathrm{msec}$, it follows that the salience of the unique stimulus requires that long a period to reach its maximum.

\section{Implications for Real-Time Models}

The present results have implications for the development of real-time models in regard to the temporal dynamics of compound stimulus representation. As may already be apparent, the adoption of the unique stimulus hypothesis would provide a ready means for incorporating a configural process without abandoning the distributive axioms. To account for the effects of CS-US interval and CS duration on CR likelihood, time-dependent changes in the salience parameter of the unique stimulus could be assigned on an empirical basis using the present results. Consequently, the revised models should provide testable deductions regarding the disparity between responding to a compound and its components following more complex manipulations, as if, for example, both components were presented simultaneously but one component had a shorter duration than the other.

As mathematical devices, the real-time models would have little trouble incorporating a unique stimulus hypothesis. However, the unique stimulus hypothesis conflicts to some extent with the wider logic of the real-time models. In particular, the Sutton and Barto (1981) model is intended to represent the properties of a neuron-like adaptive element that is part of a wider network of simi- lar neuron-like elements. Presumably, each element receives inputs from each stimulus, and the likelihood of each stimulus's eliciting an output depends on a changing weight for each input connection. Within this general scheme, it remains to be resolved (1) how best to represent the unique stimulus, and (2) how best to represent the factors that produce its apparently distinctive temporal characteristics. As to the question of representing the unique stimulus, there are three possible tactics. First, each adaptive element could generate its own internal unique stimuli with its own distinctive temporal characteristics. Although this tactic is possible, it risks turning each element into a homunculus. That is to say, the notion of each element's generating internal inputs simply pushes back identification of the mechanisms underlying configural stimuli. Second, each adaptive element could receive a separate input for each of the infinite number of combinations of elementary sensory inputs. Although the nervous system may be "prewired" to represent some combinations of sensory inputs, it does not appear plausible to assume that all combinations, each with its own temporal characteristics, are intrinsically represented. Third, instead of assuming prewired representations, the sensory analyzers can be viewed as a layered network of adaptive elements that are "tuned" to significant combinations of inputs, thus synthesizing inputs that encode the compound for adaptive elements in subsequent layers (e.g., Barto, 1984; Barto, Anderson, \& Sutton, 1982; Konorski, 1967, pp. 63-108; Rumelhart, Hinton, \& Williams, 1985). For example, there may be elements on the sensory side of the network that have high thresholds and thus provide an output only if stimulated by two or more sensory inputs with sufficient combined weights to exceed the element's threshold (Rumelhart et al., 1985). To account for the dependency of compound-component disparities on relatively long CS durations, it may be inferred that high-threshold elements would require relatively long CS durations to ensure that processes of spatial and/or temporal summation by the sensory inputs would become sufficient to trigger an output from the high-threshold element.

\section{REFERENCES}

BAKER, T. W. (1972). Component dynamics within compound stimuli. In R. F. Thompson \& J. F. Voss (Eds.), Topics in learning and performance (pp. 85-103). New York: Academic Press.

BARTo, A. G. (Ed.) (1984). Simulation experiments with goal-seeking adaptive elements. (AFWAL-TR-84-1022). Wright-Patterson AFB, OH: Avionics Laboratory, Air Force Wright Aeronautical Laboratories.

Barto, A. G., Anderson, C. W., \& Sutton, R. S. (1982). Synthesis of nonlinear control surfaces by a layered associative search network. Biological Cybernetics, 43, 175-185.

Bellingham, W. P., \& Gillette, K. (1981). Spontaneous configuring to a tone-light compound using appetitive training. Learning \& Motivation, 12, 420-434.

Bellingham, W. P., Gillette-Bellingham, K., \& Kehoe, E. J. (1985). Summation and configuration in patterning schedules with the rat and rabbit. Animal Learning \& Behavior, 13, 152-164.

Chisholm, D. C., Hupka, R. B., \& Moore, J. W. (1969). Auditory 
differential conditioning of the rabbit nictitating membrane response. II. Effects of interstimulus interval and cue similarity. Psychonomic Science, 15, 125-126.

FREY, P. W. (1969). Differential rabbit eyelid conditioning as a function of age, interstimulus interval, and cue similarity. Journal of Experimental Psychology, 81, 326-333.

Gormezano, I. (1966). Classical conditioning. In J. B. Sidowski (Ed.), Experimental methods and instrumentation in psychology (pp. 385420). New York: McGraw-Hill.

Gray, T., \& Lethbridge, D. A. (1976). Configural conditioning in the CER: Loss of element strength after repeated reinforced compound CS trials. Learning \& Motivation, 7, 532-539.

Hartman, T. F., \& GRANT, D. A. (1962). Differential eyelid conditioning as a function of the CS-US interval. Journal of Experimental Psychology, 64, 131-136.

Heinemann, E. G., \& Chase, S. (1975). Stimulus generalization. In W. K. Estes (Ed.), Handbook of learning and cognitive processes: Vol. 2. Conditioning and behavior theory (pp. 305-349). Hillsdale, NJ: Erlbaum.

Holland, P. C., \& Block, H. (1983). Evidence for a unique cue in positive patterning. Bulletin of the Psychonomic Society, 21, 297-300.

Hult, C. L. (1943). Principles of behavior. New York: AppletonCentury-Crofts.

HULL, C. L. (1945). The discrimination of stimulus configurations and the hypothesis of neural afferent interaction. Psychological Review, 52, 133-139.

KAMIN, L. J. (1969). Selective association and conditioning. In N. J. Mackintosh \& F. W. K. Honig (Eds.), Fundamental issues in associative learning (pp. 42-64). Halifax: Dalhousie University Press.

KEHOE, E. J. (1982). Overshadowing and summation in compound stimulus conditioning of the rabbit's nictitating membrane response. Journal of Experimental Psychology: Animal Behavior Processes, 8 , 313-328.

KEHOE, E. J. (1986). Summation and configuration in conditioning of the rabbit's nictitating membrane response to compound stimuli. Journal of Experimental Psychology: Animal Behavior Processes, 12, 186-195.

Kehoe, E. J., Feyer, A., \& Moses, J. L. (1981). Second-order conditioning of the rabbit's nictitating membrane response as a function of the CS2-CS1 and CS1-US intervals. Animal Learning \& Behavior, 9, 304-315.

Kehoe, E. J., \& Gormezano, I. (1980). Configuration and combination laws in conditioning with compound stimuli. Psychological Bulletin, 87, 351-378.

KeHOE, E. J., \& SChreURs, B. G. (1986). Compound conditioning of the rabbit nictitating membrane response: Test trial manipulations. Bulletin of the Psychonomic Society, 24, 79-81.

KONORSKI, J. (1967). Integrative activity of the brain: An interdisciplinary approach. Chicago: University of Chicago Press.

LAMB, M. R., \& RILEY, D. A. (1981). Effects of element arrangement on the processing of compound stimuli in pigeons (Columba livia). Journal of Experimental Psychology: Animal Behavior Processes, 7, 45-58.

MACKINTOSH, N. J. (1975). A theory of attention: Variation in the associability of stimuli with reinforcement. Psychological Review, 82, 276-298.

MoOre, J. W., \& STICKNEY, K. J. (1980). Formation of attentional- associative networks in real time: Role of the hippocampus and implications for conditioning. Physiological Psychology, 8, 207-217. Pearce, J. M., \& Hall, G. (1980). A model for Pavlovian conditioning: Variations in the effectiveness of conditioned but not of unconditioned stimuli. Psychological Review, 87, 532-552.

Razran, G. (1965). Empirical codifications and specific theoretical implications of compound-stimulus conditioning: Perception. In W. F Prokasy (Ed.), Classical conditioning (pp. 226-248). New York: Appleton-Century-Crofts.

Razran, G. (1971). Mind in evolution. New York: Appleton-CenturyCrofts.

Rescorla, R. A. (1972). "Configural" conditioning in discrete-trial bar pressing. Journal of Comparative \& Physiological Psychology, 79, 307-317.

RESCORLA, R. A. (1973). Evidence for the "unique stimulus" account of configural conditioning. Journal of Comparative \& Physiological Psychology, 85, 331-338.

Rescorla, R. A., \& Wagner, A. R. (1972). A theory of Pavlovian conditioning: Variations in the effectiveness of reinforcement and nonreinforcement. In A. H. Black \& W. F. Prokasy (Eds.), Classical conditioning II (pp. 64-99). New York: Appleton-Century-Crofts.

Rumelhart, D. E., Hinton, G. E., \& Williams, R. J. (1985). Learning internal representations by error propagation (ICS Tech. Rep. No. 8506). San Diego: University of California, Institute for Cognitive Science.

SaAvedra, M. A. (1975). Pavlovian compound conditioning in the rabbit. Learning \& Motivation, 6, 314-326.

SCANDRETT, J., \& GoRmEZANO, I. (1980). Microprocessor control and A-D data acquisition in classical conditioning. Behavior Research Methods \& Instrumentation, 12, 120-125.

SCHNEIDERMAN, N. (1966). Interstimulus interval function of the nictitating membrane response in the rabbit under delay versus trace conditioning. Journal of Comparative \& Physiological Psychology, 62, $397-402$.

Sutherland, N. S., \& Mackintosh, N. J. (1971). Mechanisms of animal discrimination learning. New York: Academic Press.

SutTon, R. S., \& BARTo, A. G. (1981). Toward a modern theory of adaptive networks: Expectation and prediction. Psychological Review, 88, 135-171.

Vandercar, D. H., \& Schneiderman, N. (1967). Interstimulus interval functions in different response systems during classical discrimination conditioning of rabbits. Psychonomic Science, 9, 9-10.

WHITLOW, J. W., \& WAGNeR, A. R. (1972). Negative patterning in classical conditioning. Summation of response tendencies to isolable and configural components. Psychonomic Science, 27, 299-301.

Wickens, D. D., Nield, A. F., Tuber, D. S., \& Wickens, C. D. (1970). Classically conditioned compound-element discrimination as a function of length of training, amount of testing and CS-UCS interval. Learning \& Motivation, 1, 95-109.

Young, D. B., \& PEARCE, J. M. (1984). The influence of generalization decrement on the outcome of a feature-positive discrimination. Quarterly Journal of Experimental Psychology, 36B, 331-352.

(Manuscript received August 14, 1985 revision accepted for publication March 3, 1986.) 